Background We evaluated the effect of once-daily tiotropium Respimat ${ }^{\circledR} 5 \mu \mathrm{g}$ on lung function, asthma exacerbation and asthma symptom control among patients with symptomatic asthma receiving inhaled corticosteroids (ICS; $\geq 800 \mu \mathrm{g} /$ day budesonide or equivalent) + long-acting $\beta_{2}$-agonist (LABA).

Methods Data were pooled from two replicate, double-blind, placebo-controlled, 48-week, parallel-group studies of once-daily tiotropium $5 \mu \mathrm{g}$ versus placebo, both delivered via the Respimat $^{\circledR}$ SoftMist ${ }^{\mathrm{TM}}$ inhaler (PrimoTinA-asthma ${ }^{\circledR}$ : NCT00772538, NCT00776984). Eligible patients had: $\geq 5$-year history of asthma diagnosed before the age of 40 years; seven-question Asthma Control Questionnaire (ACQ-7) score of $\geq 1.5$; experienced $\geq 1$ exacerbation during the previous year. Patients were either lifelong non-smokers, or ex-smokers ( $<10$ pack-years) who quit smoking $\geq 1$ year before study enrolment. Exclusion criteria included diagnosis of chronic obstructive pulmonary disease. Coprimary end points in individual trials: peak forced expiratory volume in 1 second $\left(\mathrm{FEV}_{1}\right)$ within $3 \mathrm{~h}$ post-dose $(0-3 \mathrm{~h})$ and trough $\mathrm{FEV}_{1}$. A co-primary end point in pooled data was time to first severe exacerbation; secondary end points included time to first episode of asthma worsening and ACQ-7 response. Post hoc efficacy analyses were performed.

Results 912 patients were randomised to receive tiotropium Respimat $^{\circledR}(n=456)$ or placebo Respimat ${ }^{\circledR}(n=456)$. At Week 48, tiotropium Respimat ${ }^{\circledR}$ was associated with statistically significant improvements versus placebo Respimat ${ }^{\circledR}$ in peak $\mathrm{FEV}_{1(0-3 \mathrm{~h})}$ (adjusted mean difference $100 \mathrm{~mL}$; 95\% confidence interval: 52, $148 ; \mathrm{p}<0.0001$ ) and trough $\mathrm{FEV}_{1}$ (adjusted mean difference 62 $\mathrm{mL} ; 95 \%$ confidence interval: 18,$106 ; \mathrm{p}=0.006$ ). Time to first severe asthma exacerbation was significantly longer with tiotropium Respimat ${ }^{\circledR}$ versus placebo Respimat ${ }^{\circledR}$ (282 vs 226 days, respectively; hazard ratio $0.79 ; \mathrm{p}=0.034)$, as was time to first episode of asthma worsening (315 vs 181 days, respectively; hazard ratio $0.69 ; \mathrm{p}<0.0001)$. At Week 24, ACQ-7 responder rate was significantly higher with tiotropium Respimat ${ }^{\circledR}$ (53.9\%) versus placebo Respimat ${ }^{\circledR}$ (46.9\%; odds ratio 1.32; $\left.\mathrm{p}=0.0427\right)$. Conclusion Once-daily tiotropium Respimat ${ }^{\circledR}$ add-on to ICS + LABA improves lung function, reduces risk of severe asthma exacerbation and asthma worsening, and significantly improves asthma symptom control compared with placebo Respimat ${ }^{\circledR}$ in patients with symptomatic asthma.

\section{S92 EFFICACY OF ONCE-DAILY TIOTROPIUM RESPIMAT® 5 $\mu G$ FROM FIVE PHASE III TRIALS IN ADULTS WITH SYMPTOMATIC ASTHMA}

${ }^{1} \mathrm{D}$ Price, ${ }^{2} \mathrm{ED}$ Bateman, ${ }^{3} \mathrm{P}$ Paggiaro, ${ }^{4} \mathrm{~A}$ Kaplan, ${ }^{5} \mathrm{M}$ Engel, ${ }^{5} \mathrm{H}$ Schmidt, ${ }^{5} \mathrm{P}$ Moroni-Zentgraf, ${ }^{6}$ HAM Kerstjens. ${ }^{1}$ Institute of Applied Health Sciences, University of Aberdeen, Aberdeen, UK; ${ }^{2}$ University of Cape Town, Cape Town, South Africa; ${ }^{3}$ University of Pisa, Pisa, Italy; ${ }^{4}$ Family Physician Airways Group of Canada, Ontaria, Canada; ${ }^{5}$ Boehringer Ingelheim Pharma GmbH and Co. KG, Biberach an Der Riss, Germany; ${ }^{6}$ University Medical Center Groningen, Groningen, The Netherlands

\subsection{6/thoraxjnl-2014-206260.98}

Background Recent clinical trials have indicated that the longacting antimuscarinic agent tiotropium, a once-daily long-acting bronchodilator, may provide benefit to patients with symptomatic asthma. We investigated primary efficacy data (lung function, risk of severe exacerbation and seven-question Asthma Control Questionnaire [ACQ-7] response) from five Phase III, randomised, double-blind, parallel-group trials that evaluated the efficacy and safety of once-daily tiotropium add-on versus placebo add-on (all tiotropium doses delivered via the Respimat ${ }^{\circledR}$

\begin{tabular}{|c|c|c|c|}
\hline & \multicolumn{3}{|c|}{ Adjusted mean of difference in response from placebo $(\mathrm{mL})$} \\
\hline & $\begin{array}{l}\text { PrimoTinA-asthma } \\
\text { (Week 24) }\end{array}$ & $\begin{array}{l}\text { MezzoTinA-asthma }{ }^{\circledR} \\
\text { (Week 24) }\end{array}$ & $\begin{array}{l}\text { GraziaTinA-asthma }{ }^{\circledR} \\
\text { (Week 12) }\end{array}$ \\
\hline & $\begin{array}{l}\text { Tiotropium } \\
\text { Respimat }^{\circledR} 5 \mu \mathrm{g}^{\mathrm{a}} \\
(\mathrm{n}=456)\end{array}$ & $\begin{array}{l}\text { Tiotropium } \\
\text { Respimat }^{\circledR} 5 \mu \mathrm{g}^{\mathrm{a}} \\
(\mathrm{n}=517)\end{array}$ & $\begin{array}{l}\text { Tiotropium } \\
\text { Respimat }^{\circledR} 5 \mu \mathrm{g} \\
(\mathrm{n}=155)\end{array}$ \\
\hline Peak FEV ${ }_{1(0-3 h)}$ & $110(p<0.0001)$ & $185(p<0.0001)$ & $128(p=0.0005)$ \\
\hline Trough FEV ${ }_{1}$ & $93(p=0.0058)$ & $146(p<0.0001)$ & $122(p=0.0010)$ \\
\hline $\mathrm{FEV}_{1} \mathrm{AUC}_{(0-3 \mathrm{~h})}$ & $107(p<0.0001)$ & $182(p<0.0001)$ & $125(p=0.0003)$ \\
\hline Peak $\mathrm{FVC}_{(0-3 h)}$ & $87(p=0.0050)$ & $95(p<0.0001)$ & $57(p=0.1714)$ \\
\hline \multicolumn{4}{|c|}{$\begin{array}{l}\text { aPooled data } \\
\text { AUC, area under the curve; } \text { FEV }_{1} \text {, forced expiratory volume in } 1 \text { second; FVC, forced vital } \\
\text { capacity }\end{array}$} \\
\hline
\end{tabular}

SoftMist $^{\mathrm{TM}}$ inhaler) in adults with symptomatic asthma on inhaled corticosteroid (ICS) \pm long-acting $\beta_{2}$-agonist (LABA) maintenance therapy.

Methods Two 48-week trials of tiotropium Respimat ${ }^{\circledR} 5 \mu \mathrm{g}$ (PrimoTinA-asthma ${ }^{\circledR}:$ NCT00776984, NCT00772538) in patients on high-dose ICS ( $\geq 800 \mu \mathrm{g}$ budesonide or equivalent) + LABA; two 24-week trials of tiotropium Respimat ${ }^{\circledR} 5 \mu \mathrm{g}$ and $2.5 \mu \mathrm{g}$ (MezzoTinA-asthma ${ }^{\circledR}$ : NCT01172808, NCT01172821) in patients on moderate-dose ICS (400-800 $\mu \mathrm{g}$ budesonide or equivalent); one 12-week trial of tiotropium Respimat ${ }^{\circledR} 5 \mu \mathrm{g}$ and $2.5 \mu \mathrm{g}$ (GraziaTinA-asthma ${ }^{\circledR}$ : NCT01316380) in patients on low-dose ICS (200-400 $\mu$ g budesonide or equivalent).

Results 3476 patients were treated, of whom 1128 received tiotropium Respimat ${ }^{\circledR} 5 \mu \mathrm{g}$. Once-daily tiotropium Respimat ${ }^{\circledR} 5 \mu \mathrm{g}$ significantly improved lung function (Table) in patients with not fully controlled asthma receiving low- to high-dose ICS. In addition, tiotropium Respimat ${ }^{\circledR} 5 \mu \mathrm{g}$ reduced the risk of severe exacerbations versus placebo (co-primary end point) in patients on high-dose ICS + LABA (hazard ratio 0.79; p = 0.0343), and there was an increase in ACQ-7 responder rate (co-primary end point) with the $5 \mu \mathrm{g}$ dose (odds ratio $1.32 ; \mathrm{p}=0.0308$ ) compared with placebo in patients on moderate-dose ICS.

Conclusion Once-daily tiotropium Respimat ${ }^{\circledR}$ significantly improves lung function in adult patients with symptomatic asthma receiving a range of doses of ICS, including even highdose ICS + LABA, suggesting a potential role for this treatment as add-on to ICS in adults with symptomatic asthma.

\section{S93 A PROSPECTIVE STUDY INVESTIGATING EXACERBATIONS, HEALTHCARE UTILISATION AND HEALTH ECONOMIC INDICATORS IN OMALIZUMAB TREATED SEVERE ALLERGIC ASTHMA PATIENTS - RESULTS FROM AN INTERIM ANALYSIS OF THE APEX II STUDY}

${ }^{1} \mathrm{M}$ Masoli, ${ }^{2} \mathrm{~A}$ Menzies-Gow, ${ }^{3} \mathrm{~L}$ Dobson, ${ }^{4} \mathrm{JB}$ Moriaria, ${ }^{5} \mathrm{R}$ Allcock, ${ }^{6} \mathrm{R}$ Niven. ${ }^{1}$ Derriford Hospital, Derriford, UK; ${ }^{2}$ Royal Brompton Hospital, London, UK; ${ }^{3}$ Torbay Hospital, Torbay, UK; ${ }^{4}$ Hull Royal Infirmary, Hull, UK; ${ }^{5}$ Queen Elizabeth Hospital Gateshead, Gateshead, UK; ${ }^{6}$ University Hospital of South Manchester, Manchester, UK

\subsection{6/thoraxjn-2014-206260.99}

Background A previous retrospective study of UK clinical practice demonstrated that omalizumab was associated with reduced exacerbations and healthcare utilisation in severe allergic asthmatics. 
Aim This multicentre observational study was conducted to confirm the observed retrospective findings prospectively in UK clinical practice.

Methods Retrospective data were collected in the 12 months prior to and prospective data for up to 12 months following omalizumab initiation. The primary endpoint was the change in mean daily OCS dosage (reported previously). Secondary endpoints included changes in mean exacerbation frequency (defined as requiring hospital admission or Accident and Emergency (A\&E) attendance and/or a course of OCS (dosage increase of at least $10 \mathrm{mg} /$ day for at least 3 days)), healthcare utilisation and missed days in education or at work.

Results 235 patients were enrolled in the study at end December 2013 in 22 UK centres. Data for interim analysis were examined from patients with 12 months of assessment at database lock (n $=85$, females, 54\%, mean $( \pm \mathrm{SD})$ age $44 \mathrm{yr}( \pm 13.2)$, mean $( \pm S D)$ duration of asthma $26 \mathrm{yr}( \pm 14.0))$. At the 16 weeks assessment $74 / 85$ (87\%) patients were classified as responders to omalizumab treatment. Comparing the 12 month periods prior to and following initiation of omalizumab, mean total exacerbations decreased by $51 \%$ from (mean, \pm SD) $4.25 \pm 2.73$ to 2.07 \pm 2.01 (mean difference 2.18, $\mathrm{p}<0.001$ ), while mean exacerbations involving hospital visits decreased by $61 \%$ from $1.52 \pm$ 2.00 to $0.59 \pm 1.25$ (difference $0.93, \mathrm{p}<0.001$ ). A\&E attendances were reduced from 54 to $19(\mathrm{p}<0.01)$ and inpatient hospitalisations from 85 to 36 ( $p<0.001)$. The percentage of average days absent from work or education due to sickness was more than halved in the 12 months pre and post omalizumab initiation reducing from $19.6 \%$ to $7.72 \%(n=27, \mathrm{p}<0.05)$.

Conclusions The data prospectively confirms that omalizumab is associated with significant reduction in exacerbations, healthcare utilisation and societal burden in severe allergic asthma patients as was reported in the retrospective study.

\section{S94 A PROSPECTIVE STUDY INVESTIGATING ORAL CORTICOSTEROID (OCS) USE AND QUALITY OF LIFE IN OMALIZUMAB TREATED SEVERE ALLERGIC ASTHMA PATIENTS - RESULTS FROM AN INTERIM ANALYSIS OF THE APEX II STUDY}

${ }^{1} \mathrm{R}$ Chaudhuri, ${ }^{2} \mathrm{~A}$ Menzies-Gow, ${ }^{3} \mathrm{H}$ Khachi, ${ }^{4} \mathrm{~S}$ Hand, ${ }^{5} \mathrm{R}$ Gore, ${ }^{6} \mathrm{R}$ Niven. ${ }^{1}$ Gartnavel General Hospital, Glasgow, UK; ${ }^{2}$ Royal Brompton, London, UK; ${ }^{3}$ London Chest Hospital, London, UK; ${ }^{4}$ Prince Charles Hospital, Merthyr Tydfil, UK; ${ }^{5}$ Lister Hospital, Stevenage, UK; ${ }^{6}$ University Hospital of South Manchester, Manchester, UK

\subsection{6/thoraxjnl-2014-206260.100}

Background A previous retrospective study of UK clinical practice demonstrated that omalizumab reduced OCS burden.

Aim This multi-centre observational study was conducted to confirm the observed retrospective findings prospectively.

Methods Retrospective data were collected in the 12 months prior to omalizumab, while prospective data were collected at 16 weeks, 8 and 12 months following initiation. The primary endpoint was the change in mean daily OCS dose in the 12 months pre and post omalizumab initiation. Secondary endpoints included changes in ACT and AQLQ scores in the 12 months pre and post omalizumab initiation.

Results 235 patients were enrolled by the end December 2013 in 22 UK centres. Data for interim analysis were examined from patients who had 12 months assessment at database lock $(\mathrm{n}=85,54 \%$ females, mean $( \pm \mathrm{SD})$ age $44 \mathrm{yr}( \pm 13.2)$, mean $( \pm S D)$ duration of asthma $26 \mathrm{yr}( \pm 14.0))$. At the 16 weeks assessment $74 / 85(87 \%)$ patients were classified as responders to

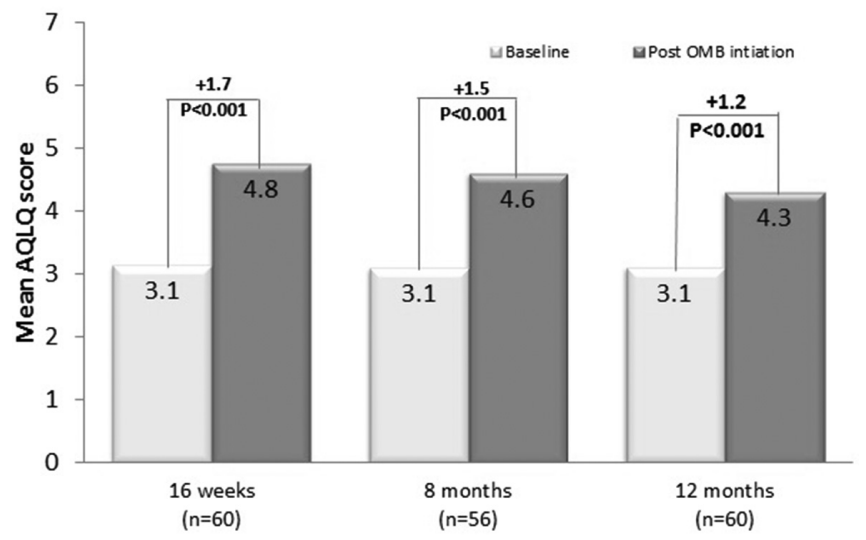

Abstract S94 Graph 1 Mean AQLQ score pre and post omalizumab initiation - ITT group

omalizumab treatment. At 12 months, mean daily OCS dose decreased by $25 \%(\mathrm{n}=85, \mathrm{p}<0.001)$ from $10.77 \mathrm{mg} /$ day $( \pm 7.87)$ to $8.08 \mathrm{mg} /$ day $( \pm 8.39)$ and $55 \%(\mathrm{n}=46 / 84)$ of patients stopped OCS. 71\% $(\mathrm{n}=60 / 85)$ of patients stopped or reduced OCS by $\geq 20 \%$. Comparing the 12 months periods prior to and following initiation of omalizumab, the mean ACT score improved from $9.8( \pm 4.8)$ to $14.2( \pm 5.2)(\mathrm{n}=75$, $\mathrm{p}<0.001)$ and the mean AQLQ score improved from 3.1 $( \pm 1.3)$ to $4.3(1.46)$ ( $\mathrm{n}=60, \mathrm{p}<0.001)$ [Graph 1].

Conclusions The data prospectively confirms that omalizumab is associated with statistically and clinically significant reduction in OCS and statistically and clinically significant improvement in asthma symptom control and quality of life.

\section{S95 DOUBLE-BLIND MULTI-CENTRE RANDOMISED CONTROLLED TRIAL OF VITAMIN D3 SUPPLEMENTATION IN ADULTS WITH INHALED CORTICOSTEROID-TREATED ASTHMA (VIDIAS)}

${ }^{1}$ AR Martineau, ${ }^{1}$ BD MacLaughlin, ${ }^{1} \mathrm{RL}$ Hooper, ${ }^{1} \mathrm{NC}$ Barnes, ${ }^{1} \mathrm{DA}$ Jolliffe, ${ }^{2} \mathrm{AB}$ Choudhury, ${ }^{3}$ RK Rajakulasingam, ${ }^{3} \mathrm{~A}$ Bhowmik, ${ }^{4} \mathrm{DE}$ Simcock, ${ }^{1} \mathrm{~J}$ Grigg, ${ }^{5} \mathrm{CJ}$ Corrigan, ${ }^{5} \mathrm{CM}$ Hawrylowicz, ${ }^{1} \mathrm{CJ}$ Griffiths. 'Queen Mary University of London, London, UK; ${ }^{2}$ Queen's Hospital, Romford, UK; ${ }^{3}$ Homerton Hospital, London, UK; ${ }^{4}$ Royal London Hospital, London, UK; ${ }^{5}$ King's College London, London, UK

\subsection{6/thoraxjnl-2014-206260.101}

Introduction and objectives Asthma exacerbations are commonly precipitated by viral upper respiratory infections (URI). Vitamin $D$ insufficiency associates with susceptibility to URI in patients with asthma. A recent vitamin $\mathrm{D}$ trial in adults with asthma reported a trend towards reduced exacerbation risk in the intervention arm as a secondary outcome. Trials of vitamin $\mathrm{D}$ in adults with asthma with incidence of exacerbation and URI as primary outcome are lacking. We therefore conducted a multicentre randomised controlled trial of vitamin $\mathrm{D}_{3}$ supplementation in adults with asthma with co-primary outcomes of severe exacerbation and URI.

Methods Two hundred and fifty adults with inhaled corticosteroid (ICS)-treated asthma were allocated to receive six 2-monthly oral doses of $3 \mathrm{mg}$ vitamin $\mathrm{D}_{3}$ or placebo over one year. Co-primary outcomes were time to first severe exacerbation and time to first URI. Sub-group analyses were performed to determine whether effects of supplementation were modified by baseline vitamin $\mathrm{D}$ status or genotype for thirty-four single nucleotide polymorphisms in eleven vitamin D pathway genes. 